${ }^{5}$ The Australasian Faculty of Occupational and Environmental Medicine, Perth, Australia

${ }^{6}$ International Labour Office, Geneva, Switzerland

\section{1a ON THE UV EXPOSURE OF WORKERS. WHAT DO WE KNOW?}

M Wittlich. Institute for Occupational Safety and Health (IFA), Sankt Augustin, Germany

\subsection{6/oemed-2018-ICOHabstracts. 1211}

Introduction We are exposed to solar ultraviolet radiation (UVR) every day, during work and leisure time. To date, there is only little knowledge about the level of irradiance. Already in 1992, UVR has been graded a group 1 carcinogen by the International Agency for Research on Cancer (IARC). In an ageing society, along with an ideal of a brown skin, non-melanoma skin cancer (NMSC) incidence rates rapidly increase.

Methods For risk assessment and deduction of protective measures, real measured data serve best. Regarding solar UVR exposure, long-term personal dosimetry measurements is required. With GENESIS-UV, we designed a suitable system. With only little impairment, each test persons measures autonomously. Data are transferred via mobile service or internet to a data server once a week automatically. GENESIS-UV has proven to be feasible in collaborations in the whole world without any changes in the system.

Results Since 2014, about 800 test persons delivered data points representing about 80000 days of measurement - in Germany. We derived the annual irradiance for more than 100 occupations, and far more occupational activities as well. Interestingly, the irradiance values for the occupations cover a very wide range (www.dguv.de/genesis). Going deeper into the occupational activities, prevention-relevant information could be obtained. The measurements have been expanded onto an European level since 2016.

Discussion Outdoor workers have to be protected from UVR exposure. During working hours, their exposure can be up to 4.5 times the leisure dose. Our approach from occupations to occupational activities enables us to suggest very distinct protective measures, and drawing a full picture of workers exposure. Particularly, we showed that already short exposure times may lead to a notable hazard. Thus, the definition of an outdoor worker has to be reviewed. The study with GENESIS-UV is by far the largest study on UV irradiance of workers worldwide.

\section{$1651 \mathrm{~b}$ PHOTOAGING IN OUTDOOR WORKERS: MARKER OF CUMULATIVE UVR EXPOSURE, RISK FACTOR OR OCCUPATIONAL DISEASE?}

${ }^{1} \mathrm{P}$ Sartorelli, ${ }^{1} \mathrm{G}$ D'Hauw, ${ }^{2} \mathrm{~V}$ Paolucci. 'Unit of Occupational Medicine AOU Senese, Department of Medical Biotechnology, University of Siena, Siena, Italy; ${ }^{2}$ UF PISLL AUSL Tuscany South-East, Grosseto, Italy

\subsection{6/oemed-2018-ICOHabstracts.1212}

Introduction Photoaging is characterised clinically by wrinkle formation and pigmentary alterations and histologically by deposition of elastotic material in the dermal connective tissue of the dermis (solar elastosis). These undesirable changes, in addition to an increased fragility of the skin, have an important epidemiologic significance because sun damaged skin increases the incidence of non melanoma skin cancers
(NMSC). For this photoaging is a real medical problem, not just an aesthetic concern.

How to measure photoaging There is no single method available to give accurate quantification of the degenerative changes associated with photodamage. In the last few years a number of authors used different methods as a measure of photoaging (e.g. confocal microscopy, microtopography and photographic scales). At the moment the3re is no agreement on how to assess photoaging.

How to consider occupational photoaging The functional and anatomical damage from solar radiation being characteristic, photoaging would be considered as a chronic disease. However there is a lack of methods of determining the level of photodamage and distinguishing photoaging from chronologic ageing. Today the better knowledge of the pathophysiological mechanisms of photoaging allows the study of photo(ageing) protective substances and of care for photoaged human skin. In this sense skin photodamage in outdoor workers could be considered as a risk factor.

Conclusions Even if photoaging is determined by a dose-dependent anatomical damage, considering it as an occupational disease would be not appropriate. Clinical features of photoaged skin can be useful to characterise the cumulative exposure level in working populations, ${ }^{1}$ while in the individual cases skin photoaging represents a NMSC risk factor which must be taken into account for possible preventive and therapeutic measures.

\section{REFERENCE}

1. Sartorelli $P$, Romeo $R$, Paolucci $V$, et al. Skin photoaging in farmers professionally exposed to ultraviolet radiations. Med Lav 2013;104:24-29.

\section{C SOLAR UV EXPOSURE AND SKIN CANCER IN WORKERS}

SM John. Dept. Dermatology, Environmental Medicine, Health Theory, University of Osnabrueck, Germany

\subsection{6/oemed-2018-ICOHabstracts. 1213}

UV radiation (UVR) is invisible to the human eye, so is also, at least according to the official statistics in most countries, the prevalence of skin cancer caused by UVR at the workplace. For that reason, skin cancer by UVR (mainly actinic keratosis, squamous cell carcinoma and basal cell carcinoma) is a mayor challenge, considering that it is the most frequent and fastest growing occupational malignancy. According to EUOSHA more than 14.5 million workers across the EU are regularly working outdoors by $\geq 75 \%$ of their daily working hours. Thus, outdoor workers are in need of targeted protection against UVR, representing the group I definition for a complete carcinogen to humans according to IARC. Specific prevention measures, including workers education, early diagnosis and medical screening are crucial to minimise the risks and to reduce morbidity. Few European countries recognise occupational skin cancer by UVR as an occupational disease. Yet, even in those few countries, workers with skin cancers related to chronic, work-related solar UVR exposure are not granted legal recognition because under-reporting is tremendous. For instance, in Denmark, in the decennium after introducing of recognition in 2000, only 35 cases had been legally acknowledged as occupational. Recent German figures may provide an estimate of the disease burden. Within the first 24 months from its recognition (2015), more than 8000 cases of occupational 'cutaneous squamous cell carcinoma or multiple actinic keratoses' are notified each year, making it the most 
frequent occupational disease e.g. in agriculture and construction, as well as the most frequent occupational cancer of all branches. The magnitude of affected workers and recent dosimetric UVR measurements showing high annual exposures (>600 SED) are currently stimulating regulatory efforts for improved workplace prevention. The recognition of UVR induced skin cancer as an occupational disease, has proven to be pivotal to this approach.

\section{1d OCCUPATIONAL UV EXPOSURE AND THE EYE}

A Modenese. University of Modena and Reggio Emilia, Modena, Italy

\subsection{6/oemed-2018-ICOHabstracts.1214}

Ultraviolet (UV) and blue-light components of optical radiation can affect the eye with a photochemical mechanism; both acute and/or long term effects can be induced. By large, the most diffuse source of optical radiation is Solar Radiation (SR) that includes both components. Among factors influencing SR exposure one of the most important is outdoor work: only in Europe outdoor-workers (OWs) are about 15 million. Another factor specifically relevant to the eye is reflection as, for anatomical reasons, the eye is less protected from reflected rays. As a consequence the presence of highly reflecting surfaces, like fresh snow or water, can increase eye exposure. In OWs various adverse chronic eye effects, involving different structures of the eye, can be found, as pterygium, cataract and macular degeneration. We reviewed scientific studies on eye effects of optical radiation in OWs. The results confirm an increased risk of the abovementioned adverse effects, but knowledge on various aspects is largely insufficient. Among relevant aspects deserving further studies are the evaluation of lifetime ocular exposure to ultraviolet radiation and blue-light considering both occupational and leisure activities, and possibly integrating subjective questionnaires data with objective data, as UV effective irradiance, available through meteo-climatic databases or field measurements. Individual aspects to be adequately investigated must include among other, also the possible presence of reflection, protective habits as the use of hats (type, frequency, etc.) and of sunglasses (frequency, shape, UV/blue light filters, etc). These aspects are extremely important especially for the development of more adequate preventive measures.

\section{1e SOLAR ULTRAVIOLET EXPOSURE - A REVIEW OF RISKS AND PREVENTIVE STRATEGIES IN AUSTRALIAN WORKPLACES}

PA Connaughton. The Australasian Faculty of Occupational and Environmental Medicine, Perth, Australia

\subsection{6/oemed-2018-ICOHabstracts.1215}

Introduction Ultraviolet(UV) radiation in the form of sunlight is Australia's most prevalent occupational carcinogen. It is estimated that $37 \%$ of the male working population and $8 \%$ of the female working population are significantly exposed to solar radiation at work.

Methods A review was performed of the current research literature, together with published national policies and best practice guidelines.
Results UV radiation exposure is the major cause of melanoma and non-melanoma skin cancer (NMSC). Australia has the highest incidence of melanoma in the world and skin cancer accounts for over $80 \%$ of all new cases of cancer diagnosed each year. Although sun protection is used by $95 \%$ of those exposed at work, only $9 \%$ are fully protected.

A 2015 study estimated that 7220 melanomas occurring in Australia in 2010 could be attributed to UV radiation exposure. The incidence of melanoma in those under the age of 25 is stable and is believed to be due to improved sun protection behaviours from education programs, although it may partly relate to the change in the population racial mix.

Evidence shows that a wide range of measures can be effective in reducing the impact of skin cancer. Australia now has extensive prevention programs and it has been estimated that the return on a national skin cancer prevention media campaign is approximately $\$ 2.32$ for every dollar invested, through reduced healthcare costs.

Conclusion This review summarises the impact of UV exposure on skin cancer prevalence in Australia. The policy priorities include reducing UV exposures, education programs and early intervention. These strategies also have the potential for broader applicability in the prevention of other occupational risks.

\section{$1651 \mathrm{f}$ ILO ACTIVITIES FOR THE PREVENTION OF THE RISK RELATED TO OCCUPATIONAL EXPOSURE TO SOLAR UV}

S Niu. International Labour Office, Geneva, Switzerland

\subsection{6/oemed-2018-ICOHabstracts. 1216}

Introduction Excessive exposure to solar UV radiation is a relevant risk factor for outdoor workers, inducing various acute and chronic adverse health effects. In particular chronic exposure can cause skin and eye cancer mainly by DNA mutations induction (e.g. in the p53 tumour suppressor gene and telomerase gene) and immunosuppression. The protection of the worker against sickness, disease and injury arising out of employment is one of the tasks assigned to the International Labour Organisation (ILO) in the Preamble of its Constitution: the protection against risks from UV exposure falls naturally within these tasks. The ILO uses various means of action to give governments and employers' and workers' organisations the necessary help in drawing up and implementing programmes for the control of workplace risk factors, including solar UV, as international standards in the form of legal instruments, codes of practice, practical manuals, training materials and education and training and technical cooperation. Examples are the Safety and Health in Agriculture Convention (No. 184) and Recommendation (No. 192), and the List of Occupational Diseases Recommendation (No. 194). Specific sections devoted to UV protection are included in the ILO codes of practice on Safety and Health in Agricultural Work, and on Ambient Factors in the Workplace. The ILO also produces guidance documents in collaboration with the ICNIRP and the WHO on workplace UV protection: they provide guidance on workplace safety and health measures and procedures that will lead to higher standards of safety for all personnel engaged in the operation which gives rise to occupational exposure to UV. Furthermore, the ILO collects information on good workplace practice on protection of workers against UV radiation and on the identification and recognition of diseases as 